\title{
Special issue on papers from the Latin American conference on applications of powder diffraction
}

Early last year, Professor Eduardo Granado and Professor José Miguel Delgado, both of the organizing committee of the Latin American Workshop on Applications of Powder Diffraction and Mini-Course on Methods of Powder Diffraction (held in Campinas, Brazil from April 16th to 20th, 2007), suggested that papers presented at this conference be published in Powder Diffraction. After discussions with Professor Granado, we came to an agreement to publish representative papers from this conference in a special issue Powder Diffraction. This special issue is the first supplementary issue dedicated to papers presented at an international X-ray conference.

Although I did not attend the conference, I learned from the conference abstract books that there were 141 invited and contributed papers, which covered many areas of powder diffraction applications, such as crystal structure and microstructure of bulk and thin film materials using X-ray and synchrotron radiation. The 30 invited papers were from around the world, including Argentina, Brazil, Cuba, France,
Germany, Italy, United Kingdom, United States, and Venezuela. The 111 contributed papers were mostly from countries in Latin America including Brazil (60\%), Argentina (20\%), Venezuela (7\%), Cuba (2\%), Mexico (2\%), Peru (2\%), and other countries including Columbia, Chile, Uruguay, Canada, Portugal, and the United States (7\%). A detailed report on the conference is given in the following editorial prepared by Professor Granado.

The representative papers were selected, reviewed, and edited by a local committee, and then sent to the staff of Powder Diffraction for final review and editing.

By publishing papers from this conference, the participants can showcase their experiments and findings to a larger audience, and our readers can learn more about advances in X-ray analysis by the Latin American scientific community.

Ting C. Huang Editor-in-Chief 